\title{
Audits and logistic regression, deciding what really matters in service processes. A case study of a government funding agency for research grants
}

\author{
Robert Wayne Samohyl ${ }^{1}$ \\ ${ }^{1}$ Federal University of Santa Catarina, Florianópolis, Brazil \\ samohyl@deps.ufsc.br
}

\begin{abstract}
Governmental agencies, businesses and nongovernmental organizations experience repetitive and out-of-date processes causing resource waste. Banks, credit card companies and tax authorities must evaluate whether creditors have fulfilled their obligations, and funding agencies should verify the use of funds by grant recipients. Here logistic regression estimates the probability of conformity of grants to the financial obligations of the researcher analyzing the correlation between characteristics of the grant and the grant's final status as approved or not. The logistic equation uncovers relevant characteristics through an analysis of false positives. A ROC curve is constructed which reveals an optimal cutoff for nonconformity.
\end{abstract}

Keywords: Logistic regression; ROC curve; probability; audits; government; research grants

\section{Introduction}

This article deals with the uncertainty of auditing formal office procedures that classify whether or not a given project that has already been completed by its authors should receive final approval from the office staff. If the project were classified by the staff as nonconforming, then it would be returned to its authors for reformulation and eventual reevaluation. Those projects that are approved are passed on to finalization including final storage. Picture if you will the process of evaluating credit applications. Credit is extended to the client of a financial institution only after a formalized review process of creditworthiness. After a certain period of time and sufficient history has been acquired on the client's activities as debtor to the institution, the client's creditworthiness is investigated, comparing the degree of creditworthiness originally assigned to the client with the results of the historical analysis. Hopefully the original evaluation should compare successfully with the facts; if approval were given then the client's credit history should manifest conformity. Another example is the governmental process of reviewing tax returns.

This kind of verification of a classification scheme usually depends upon several forms filled in with specific information and corroborated by relevant documentation. Information is checked and documents are authenticated. It is common practice to use a checklist of the most important items and corroborating documents that guide the process indicating inadequacies, and if the project is rejected it is returned to its authors for corrections. A checklist may have tens or even hundreds of items. If the checklist is the result of an historical evolution within the institution encompassing changes in management and technologies, through time it may have become repetitive and cumbersome, substantiating the need for an audit leading to the reformulation of checklist items. The in-house investigation of internal processes is called an internal audit, usually applied sporadically with the intention of uncovering activities and other elements of key processes that no longer produce value for the institution, in the case studied here to verify the correspondence between the checklist and the true state of the project accounts.

We offer a procedure based on logistic regression that identifies the degree of correlation among items of the checklist and the consequent approval or rejection of the financial. The use of the receiver operating characteristic (ROC) curve programmed in the R language (R Development Core Team (2012)) will be essential not only to evaluate the procedures under study but also to suggest changes for a simpler and more valuable process. $\mathrm{R}$ package $\mathrm{ROCR}$ is especially important for the development of this article. All calculations were done with the $\mathrm{R}$ language under the GNU license. ROC analysis has advanced mostly in the medical sciences (R. Kumar and A. Indrayan, 2011), however with the development of several $\mathrm{R}$ packages (T. Sing, O. Sander, N. Beerenwinkel, and T. Lengauer 2005) which simplify applications, the use of the ROC methodology has been spreading into other areas (O. Komori, 2009).

Quality control guidelines are easily adapted to the question of internal audits. Office bureaucracy is analogous to an industrial process, following a certain number and kind of procedures defining activities and responsible personnel who receive inputs usually in the form of verbal and written communications that are processed and then delivered to the next step of the 
process. Audits evaluate these procedures in order to eliminate unnecessary steps or combine steps to economize on resources (M. Cecchini, H. Aytug, G. J. Koehler, and P. Pathak, 2010).

Here, internal auditors in the public sector evaluate the financial side of research grants. They look to establish the conformity of the financial activity of the research project, checking for the proper use and transcription of grant finances. Based on a checklist of important items, the financial events of the project are either approved or rejected, and the conformity of project finances classified.

\section{Data}

The data is composed of 540 research projects (observations) and the respective financial accounts from a funding agency on the State level for research projects. These research projects have already suffered preliminary internal audits and have been judged either as conforming or nonconforming by the internal auditors. Consequently, the data base is constructed from a primary data source which is the original forms, bank statements and other documents submitted by the researchers at the end of their research activities. A summary of the data can be found in table 1 .

\begin{tabular}{|c|}
\hline $\begin{array}{l}\text { Approvals: Financial accounts approved (c) } \\
\text { or rejected (n). Primary response variable }\end{array}$ \\
\hline Value (in local currency - Reals) first installment \\
\hline Total value of grant \\
\hline fisjur: Beneficiary is a private person or a legal entity \\
\hline Project budget is for expenses or equipment \\
\hline Project coordinator has a doctorate \\
\hline Type of grant program \\
\hline Institution where project is located \\
\hline City where project is located \\
\hline Chamada.Pública, a specific grant program \\
\hline $\begin{array}{l}\text { Item 1, Financial accounts should be divided into } \\
\text { categories of either expenses or equipment and should } \\
\text { be separated into two distinct files and should receive } \\
\text { different process numbers. }\end{array}$ \\
\hline $\begin{array}{l}\text { Item 2, Scientific technical report has been archived at } \\
\text { the URL of the funding agency? }\end{array}$ \\
\hline $\begin{array}{l}\text { Item } 3 \text {, Balance sheet has been signed and archived at } \\
\text { the official government URL. }\end{array}$ \\
\hline $\begin{array}{l}\text { Item } 4 \text {, All receipts, boarding passes and any other } \\
\text { fiscal documents arranged in chronological order. }\end{array}$ \\
\hline $\begin{array}{l}\text { Item } 5 \text {, All monthly bank statements containing all } \\
\text { bank balances and financial movement, from the first } \\
\text { deposit until the closing of the account. }\end{array}$ \\
\hline $\begin{array}{l}\text { Item 6, If necessary, uncashed checks (but written) } \\
\text { separately listed and accounted for. }\end{array}$ \\
\hline $\begin{array}{l}\text { Item } 7 \text {, Grant funds not utilized, returned to the } \\
\text { funding agency and appropriately verified. }\end{array}$ \\
\hline $\begin{array}{l}\text { Item } 8 \text {, All bank deposits must be accounted for and } \\
\text { all appropriate forms signed by all parties. }\end{array}$ \\
\hline
\end{tabular}

Item 9, If necessary, verification that equipment has been donated to the research institution.

Item 10, Verification of payments for services and consulting.

Item 11, In order to finalize the closing out process of the entire research grant, both financial accounts and the final scientific technical report must be appropriately approved.

Item 12, Copy of contract with the funding agency and agreed work plan

Item13, Verification of extraordinary daily expenses, if necessary.

Table 1. Financial and demographic statistics

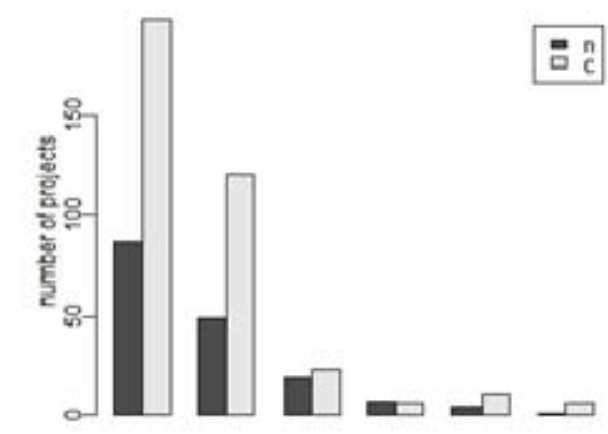

smal valued projects (hundreds of Reals to millons) large valued projects

Figure 1. Conforming and nonconforming projects by total value of the grant.

Among the variables that describe some important aspects of the research project, financial characteristics are contained in the 13 items from the checklist of obligations which lists the relevant items necessary for closing out the financial accounts of the grant. The checklist is an internal document for the internal auditors and is not seen by the researcher. Figure 1 shows the number of projects that were classified as conforming (c) or nonconforming (n) by the office staff by value of the grant, the third entry in the list of data in table 1. A quick look at figure 1 shows no relationship between value of the grant and its final disposition as conforming or not. Regardless of the value of the grant, conforming projects hover around $70 \%$ of the total. This result is later supported by the logistic regression in section 4.

\section{Contingency table.}

In the following tables, the major problem of the process under study becomes apparent, that in most cases there is little apparent correlation between the verification of the financial accounts of the grants and the items of the checklist, suggesting that the checklist needs revision. Later on, we determine through logistic regression the most important items of the checklist as 
predictors of the probability of approval limited to a small number of checklist items not always with the desired causality direction, and almost all other variables statistically insignificant.

In the contingency tables of table 2 , we test the relationship between the conformity (c) and nonconformity (n) of the grant as related to the successful approval (s) or non-approval (n) of a specific item from the checklist. Not all 12 items from the checklist are present in the table to emphasize only items that will have been chosen as relevant by the logistic equation applied in subsequent sections. For more on contingency tables see chapter 2 of Agresti, A (2002). The column marked " $n$ " defines the number of nonconforming grants and "c" conforming grants. Rows define whether an individual item from the checklist was approved or not. Entries in the table show the degree of consistency between grant approval and relevance of a checklist item. In the northwest corner of the tables, we count the number of times a specific item was not approved ( $n$ obs), however the respective financial accounts were judged as conforming (c). In principle but not always the case, a rejected item should lead to a nonconforming grant. For instance, verify the values in the last contingency table for item 12, where 53 grants while judged as conforming (c) did not pass approval for item 12 (n obs). Clearly the question is why was the grant judged as conforming given the rejection of item 12? Inconsistent results appear in all the items, which would lead us to believe that the checklist needs revision. The numbers in the northwest entry are consistent results showing the rejection (n obs) of the item and the nonconforming (n) nature of the grant. The numbers in italics are expected values based on the proportions of conforming grants and approvals of the checklist item. Essentially, if proportions were 50\%, then each entry would be $25 \%$ of the total, assuming randomness and independence. The chi-squared for each table measures the randomness of the entries in the table by comparing expected frequencies to observed. There is strong evidence of randomness for item 3 with $p$ value practically equal to 1.0 , and somewhat weaker evidence for item 4 . In other words, for these items the result of the classification procedures is no better than a random draw. All other items reject the randomness assumption. In fact, for the column of nonconforming grants, observed item rejections ( $n$ obs.) are more numerous than the expected value suggesting that office procedures are at least better than a random draw. The first contingency table relates conformity to the academic qualification of the coordinator of the research project, whether she has a doctorate. The observed count for nonconformity and no doctorate is 28 which is very close to the expected value of 32 , the expected value of a random draw. In fact, all expected values are very close to the observed for the conformity/Doctorate contingency table which leads to the chi-squared test not rejecting the hypothesis of a random draw. The chisquared test suggests that conformity is independent of the doctorate. The logistic regression estimates will elaborate on this result.

\begin{tabular}{|c|c|c|c|c|c|c|c|}
\hline \multicolumn{4}{|c|}{ Conformity } & \multicolumn{4}{|c|}{ Conformity } \\
\hline Doc & $\mathrm{n}$ & $\mathrm{c}$ & Total & Item.5 & $\mathrm{n}$ & $\mathrm{c}$ & Total \\
\hline n obs. & 28 & 74 & 102 & n obs. & 41 & 44 & 85 \\
\hline n expected & 32 & 70 & & $\mathrm{n}$ expected & 27 & 58 & \\
\hline S obs. & 125 & 267 & 392 & s obs. & 123 & 313 & 436 \\
\hline s expected & 121 & 271 & & s expected & 137 & 299 & \\
\hline Total & 153 & 341 & 494 & Total & 164 & 357 & 521 \\
\hline \multicolumn{4}{|c|}{ Pearson Chi-squared with Yates correction } & Qui $^{2}=12.31$ & g.1. $=1$ & $p=0.0004$ & \\
\hline Qui $^{2}=0.55$ & g.1. $=1$ & $p=0.45$ & & & & & \\
\hline Item.2 & $\mathrm{n}$ & $\mathrm{c}$ & Total & Item.6 & $\mathrm{n}$ & $\mathrm{c}$ & Total \\
\hline n obs. & 93 & 91 & 184 & n obs. & 48 & 74 & 122 \\
\hline $\mathrm{n}$ expected & 57 & 127 & & $\mathrm{n}$ expected & 37 & 85 & \\
\hline s obs. & 70 & 270 & 340 & s obs. & 109 & 284 & 393 \\
\hline s expected & 106 & 234 & & s expected & 120 & 273 & \\
\hline Total & 163 & 361 & 524 & Total & 157 & 358 & 515 \\
\hline Qui $^{2}=48.6$ & g.1. $=1$ & $p=0.000$ & & $\mathrm{Qui}^{2}=5.38$ & g.1. $=1$ & $p=0.02$ & \\
\hline
\end{tabular}




\begin{tabular}{|c|c|c|c|c|c|c|c|}
\hline Item.3 & $\mathrm{n}$ & $\mathrm{c}$ & Total & Item.10 & $\mathrm{n}$ & $\mathrm{c}$ & Total \\
\hline n obs. & 19 & 40 & 59 & n obs. & 47 & 55 & 102 \\
\hline $\mathrm{n}$ expected & 19 & 41 & & $\mathrm{n}$ expected & 32 & 70 & \\
\hline s obs. & 147 & 324 & 471 & s obs. & 110 & 283 & 393 \\
\hline s expected & 148 & 324 & & s expected & 125 & 268 & \\
\hline Total & 166 & 364 & 530 & Total & 157 & 338 & 495 \\
\hline Qui $^{2}=0.000$ & g.1. $=1$ & $p=0.99$ & & Qui $^{2}=11.41$ & g.1. $=1$ & $p=0.0007$ & \\
\hline Item.4 & $\mathrm{n}$ & $\mathrm{c}$ & Total & Item.12 & $\mathrm{n}$ & $\mathrm{c}$ & Total \\
\hline n obs. & 15 & 18 & 33 & n obs. & 65 & 53 & 118 \\
\hline $\mathrm{n}$ expected & 10 & 23 & & $\mathrm{n}$ expected & 36 & 82 & \\
\hline s obs. & 145 & 343 & 488 & s obs. & 93 & 305 & 398 \\
\hline s expected & 150 & 338 & & s expected & 122 & 276 & \\
\hline Total & 160 & 361 & 521 & Total & 158 & 358 & 516 \\
\hline Qui $^{2}=2.89$ & g.1. $=1$ & $p=0.0887$ & & Qui $^{2}=41.62$ & g.1. $=1$ & $p=0.0000$ & \\
\hline
\end{tabular}

Table 2. Contingency tables of the relation of conforming and nonconforming grants and some specific items of the checklist.

\section{Estimation.}

Among several possible alternatives for estimating the effect of a variable on the probability of the existence of another, logistic regression is one of the most widely used. Consider a variable $\mathrm{Y}$ which is essentially binomial having two possible states as, for example, conforming and nonconforming. At the close of a research project, the financial accounts of a research grant can be either approved as conforming or rejected as nonconforming by the funding agency. The probability of conformity is written as $P(c)$. In turn, the value of $P(c)$ may depend on a host of variables that characterize the project such as the approval of the items in the checklist, or on predictor variables such as the monetary value of the grant or the institution where the project was undertaken, among many others. The predictor variables $X_{i}$ may be quantitative or qualitative. Here we will not go into detail however, several important references on logistic regression are the following. The original methodology is from the $18^{\text {th }}$ century (Cramer, 2002). The first modern application is Reed, L. J. and J. Berkson (1929). A much respected text is Agresti (2002). The logistic equation where an interaction term has been included $\mathrm{X}_{1} * \mathrm{X}_{2}$ is

$\ln \frac{P(c)}{1-P(c)}=a+b_{1} X_{1}+b_{2} X_{2}+b_{12} X_{1} * X_{2}(1)$
Statistical results presented below have an interaction term. The left hand expression is the logit also known as the log odds. odds $=P(c) /(1-P(c))$, consequently $P(c)$ $=$

odds/(1+odds). Theoretically, the logit can vary between positive and negative infinity as $P(c)$ varies from 1 to 0 . When the logit is null, $P(c)$ is 0.5 . To better appreciate the nonlinear relationship between

$P(c)$ and the predictor variables, equation (1) can be rewritten as

$$
P(c)=\frac{e^{a+b_{1} X_{1}+b_{2} X_{2}+b_{12} X_{1} * X_{2}}}{1+e^{a+b_{1} X_{1}+b_{2} X_{2}+b_{12} X_{1} * X_{2}}}
$$

The regression procedure will estimate the values of the coefficients, and then an estimate of $P(c)$, the response variable, for specific values of $X_{i}$. Most of the variables in the data base are binary. Furthermore, the logistic regression should evaluate interaction terms and other non linearities if necessary. Consequently, the principal objective of the analysis is to determine the influence of a predictor variable $\mathrm{X}_{\mathrm{i}}$ on the value of $P(c)$. The estimated equation represents the value of the probability of project conformity when a specific item in the checklist has been approved or other characteristics are present.

The logistic equation was estimated using several different subsets of variables, and criteria for selecting 
the best subset were based on judgment of the individual significance of each coefficient and the AIC of the overall equation. The subsets included several interaction terms. In table 3, the results from the logistic regression are reported for the coefficient estimates and other appropriate statistics. While some of the results are not significant at the traditional 5\% level, these variables were not eliminated from the model for other reasons, such as the value of the AIC or due to the importance of the variable in the interaction terms. Surprisingly, even though there is 13 items in the checklist, only six items are correlated with the approval or rejection of the grant's financial accounts. Moreover, two other variables are important, whether the coordinator of the project has a doctorate (Doc) and the specific details of each grant program (CPnumber). Model fit is adequate suggested by the values of the residual deviance (393) and degrees of freedom (415).

\begin{tabular}{|c|c|c|c|c|c|c|c|c|}
\hline \multicolumn{4}{|c|}{ With interactions } & \multicolumn{5}{|c|}{ No interactions } \\
\hline Coefficients: & Estimate & Std.Error & $\mathrm{z}$ value & $\operatorname{Pr}(>|z|)$ & Estimate & Std.Error & $\mathrm{z}$ value & $\operatorname{Pr}(>|z|)$ \\
\hline Intercept & -0.358 & 1.350 & -0.265 & 0.791 & -2.600 & 0.619 & -4.203 & 0.000 \\
\hline Doc & -3.387 & 1.454 & -2.329 & 0.020 & -0.426 & 0.318 & -1.343 & 0.179 \\
\hline CP00106 & 1.822 & 0.947 & 1.924 & 0.054 & 1.908 & 0.934 & 2.044 & 0.041 \\
\hline СР00109 & 1.163 & 0.581 & 2.000 & 0.045 & 1.004 & 0.560 & 1.792 & 0.073 \\
\hline CP00110 & 2.534 & 0.823 & 3.079 & 0.002 & 2.135 & 0.791 & 2.700 & 0.007 \\
\hline CP00205 & 1.469 & 1.015 & 1.447 & 0.148 & 1.286 & 0.958 & 1.343 & 0.179 \\
\hline СР00407 & 1.763 & 0.693 & 2.543 & 0.011 & 1.592 & 0.683 & 2.332 & 0.020 \\
\hline CP01209 & -1.921 & 0.842 & -2.281 & 0.023 & -1.411 & 0.762 & -1.853 & 0.064 \\
\hline CPother & -1.597 & 0.957 & -1.670 & 0.095 & 0.449 & 0.493 & 0.910 & 0.363 \\
\hline Item. 12 & 3.229 & 0.957 & 3.372 & 0.001 & 1.373 & 0.302 & 4.542 & 0.000 \\
\hline Item. 10 & -2.682 & 1.143 & -2.347 & 0.019 & 0.557 & 0.316 & 1.765 & 0.078 \\
\hline Item.2 & 2.288 & 0.661 & 3.460 & 0.001 & 1.063 & 0.262 & 4.056 & 0.000 \\
\hline Item. 3 & -1.953 & 1.041 & -1.876 & 0.061 & -0.216 & 0.402 & -0.536 & 0.592 \\
\hline Item. 5 & 1.778 & 0.378 & 4.704 & 0.000 & 1.437 & 0.344 & 4.176 & 0.000 \\
\hline Item.6 & 0.553 & 0.289 & 1.913 & 0.056 & 0.526 & 0.279 & 1.887 & 0.059 \\
\hline Doc:CPother & 2.778 & 1.159 & 2.396 & 0.017 & & & & \\
\hline Doc:Item.12 & -1.979 & 1.008 & -1.962 & 0.050 & & & & \\
\hline Doc:Item.10 & 3.698 & 1.199 & 3.084 & 0.002 & & & & \\
\hline Doc:Item.2 & -1.454 & 0.718 & -2.026 & 0.043 & & & & \\
\hline Doc:Item.3 & 1.975 & 1.151 & 1.716 & 0.086 & & & & \\
\hline \multirow{2}{*}{\multicolumn{2}{|c|}{$\begin{array}{c}\text { Null deviance: } \\
\text { Residual deviance: }\end{array}$}} & 533.97 & $434 \mathrm{df}$ & & \multirow{2}{*}{\multicolumn{2}{|c|}{$\begin{array}{l}\text { Null deviance: } \\
\text { Residual deviance: }\end{array}$}} & 533.97 & $434 \mathrm{df}$ \\
\hline & & 393.57 & $415 \mathrm{df}$ & & & & 417.09 & $420 \mathrm{df}$ \\
\hline AIC: & 433.57 & & & & AIC: & 447.09 & & \\
\hline
\end{tabular}

Table 3. Results from logistic regressions with and without interactions equation (3).

The two regressions of table 3 are very similar. The first equation, which includes interaction terms, has been chosen as the most representative and its results will be utilized in the analysis of the next sections. The second equation has no interaction terms but is constructed with the same factors. Compare the coefficient values between the two equations for the factors which do not enter the interaction terms, in the table lightly shaded to distinguish them. Results are very similar between the two estimated equations. Furthermore, since the first equation produces better results in terms of the residual deviance and the AIC, the importance of the interaction terms, the last 5 terms in the equation, is corroborated.

The estimated equation contains 14 binary variables: 6 items from the checklist, 7 grant programs, and the doctorate. Exactly how many cases are represented by the equation? Since grants are exclusively in one unique program at a time, only one of the grant programs can be activated for a specific case, all others excluded. This means that the number of cases represented in number of possible combinations is $896\left(=7 * 2^{14-7}\right)$. However, for the sake of simplicity some reduction is possible if we eliminate those programs that do not enter the interaction terms (all programs with the exception of Cpother). There are a total of 8 binary factors remaining, Item2, Item3, Item5, Item6, Item10, Item12, Doc, Cpother, and the number of combinations is 256 $\left(2^{8}\right)$. Some of these cases, the best, the worst and the middle, are aligned in table 4 ordered by the probability of conformity $P(c)$. The last case has essentially no chance of being approved (0.001), while the chance of approval for the first case is practically certain (0.999). Another result that will merit more detail subsequently is that the absence of the doctorate (column Doc $-n$ ) is present in table 4 for both large probabilities and small. On the other hand, items 10 and 12 follow a consistent pattern in terms of best and worst probabilities. In order to get a general idea as to the structure of the equation 
and the relationship between $P(c)$ and the predictor factors, Box plots are constructed for these cases. In figures 2 and 3, we see that item 2, 5, 6 and 12 are the only factors where the probability of conforming increases with the successful approval of the item on the checklist. However, and counter-intuitively, items 3 and 10 when successfully approved diminish the probability of conformity. Note the deleterious effect of the doctorate, and the difference in variability. This result corroborates the result already seen in the preceding table that the absence (n) of the doctorate appears consistently in both highly conforming and nonconforming projects.

Because of the complex nonlinear associations in the estimated equation, a common characteristic in logistic equation estimation, in the next section, differential effects are measured and the importance of each factor determined.

\begin{tabular}{|c|c|c|c|c|c|c|c|c|}
\hline Item.2 & Item.3 & Item.5 & Item.6 & Item.10 & Item.12 & Doc & CPother & probs \\
\hline$s$ & $\mathrm{n}$ & $\mathrm{s}$ & $\mathrm{s}$ & $\mathrm{n}$ & $\mathrm{s}$ & $\mathrm{n}$ & FAI SE & 0.999 \\
\hline$s$ & $\mathrm{n}$ & $s$ & $\mathrm{n}$ & $\mathrm{n}$ & $s$ & $\mathrm{n}$ & FAI SE & 0.999 \\
\hline$s$ & $\mathrm{n}$ & $s$ & $s$ & $\mathrm{n}$ & $s$ & $\mathrm{n}$ & TRUE & 0.997 \\
\hline s & $\mathrm{n}$ & $\mathrm{n}$ & s & $\mathrm{n}$ & s & $\mathrm{n}$ & FAI SE & 0.997 \\
\hline$s$ & $s$ & $s$ & $s$ & $\mathrm{n}$ & $s$ & $\mathrm{n}$ & FAI SE & 0.996 \\
\hline$s$ & $\mathrm{n}$ & s & $\mathrm{n}$ & $\mathrm{n}$ & $s$ & $\mathrm{n}$ & TRUE & 0.995 \\
\hline $\mathrm{n}$ & $\mathrm{n}$ & $\mathrm{s}$ & s & $\mathrm{n}$ & $s$ & $\mathrm{n}$ & FAISE & 0.995 \\
\hline s & $\mathrm{n}$ & $\mathrm{n}$ & $\mathrm{n}$ & $\mathrm{n}$ & $s$ & $\mathrm{n}$ & FAI SE & 0.994 \\
\hline s & s & s & $\mathrm{n}$ & $\mathrm{n}$ & s & $\mathrm{n}$ & FAI SE & 0.993 \\
\hline$s$ & $\mathrm{n}$ & $s$ & $s$ & $s$ & $s$ & $\mathrm{n}$ & FAISE & 0.992 \\
\hline$s$ & $\mathrm{n}$ & $\mathrm{n}$ & $\mathrm{s}$ & $\mathrm{n}$ & $\mathrm{n}$ & $\mathrm{n}$ & TRUE & 0.708 \\
\hline s & $\mathrm{n}$ & $\mathrm{n}$ & $\mathrm{n}$ & $s$ & $s$ & $\mathrm{n}$ & TRUE & 0.707 \\
\hline $\mathrm{n}$ & s & s & s & s & s & s & FAI SE & 0.706 \\
\hline $\mathrm{n}$ & $\mathrm{n}$ & s & $s$ & $s$ & $s$ & $s$ & FAISE & 0.701 \\
\hline $\mathrm{n}$ & s & s & s & s & $\mathrm{n}$ & s & TRUE & 0.691 \\
\hline $\mathrm{n}$ & $\mathrm{n}$ & s & $s$ & $s$ & $\mathrm{n}$ & $s$ & TRUE & 0.686 \\
\hline $\mathrm{n}$ & $\mathrm{n}$ & $\mathrm{n}$ & s & s & s & $\mathrm{n}$ & FAI SE & 0.677 \\
\hline s & s & s & s & $\mathrm{n}$ & $\mathrm{n}$ & $\mathrm{n}$ & TRUE & 0.671 \\
\hline$s$ & $s$ & s & $\mathrm{n}$ & s & $s$ & $\mathrm{n}$ & TRUE & 0.669 \\
\hline$s$ & $s$ & s & s & $\mathrm{n}$ & s & s & FAI SE & 0.667 \\
\hline s & $\mathrm{n}$ & s & s & $\mathrm{n}$ & $\mathrm{s}$ & $s$ & FAISE & 0.662 \\
\hline $\mathrm{n}$ & $\mathrm{s}$ & $\mathrm{n}$ & $\mathrm{n}$ & $\mathrm{n}$ & $\mathrm{n}$ & $\mathrm{n}$ & TRUE & 0.020 \\
\hline $\mathrm{n}$ & $\mathrm{n}$ & $\mathrm{n}$ & s & s & $\mathrm{n}$ & $\mathrm{n}$ & TRUE & 0.017 \\
\hline $\mathrm{n}$ & $s$ & s & s & s & $\mathrm{n}$ & $\mathrm{n}$ & TRUE & 0.014 \\
\hline s & s & $\mathrm{n}$ & $\mathrm{n}$ & s & $\mathrm{n}$ & $\mathrm{n}$ & TRUE & 0.013 \\
\hline $\mathrm{n}$ & s & $\mathrm{n}$ & s & s & $\mathrm{n}$ & $\mathrm{n}$ & FAI SE & 0.012 \\
\hline $\mathrm{n}$ & $\mathrm{n}$ & $\mathrm{n}$ & $\mathrm{n}$ & $s$ & $\mathrm{n}$ & $\mathrm{n}$ & TRUE & 0.010 \\
\hline $\mathrm{n}$ & $s$ & $s$ & n & $s$ & n & n & TRUE & 0.008 \\
\hline $\mathrm{n}$ & $s$ & $\mathrm{n}$ & $\mathrm{n}$ & $s$ & $\mathrm{n}$ & $\mathrm{n}$ & FAI SE & 0.007 \\
\hline $\mathrm{n}$ & s & $\mathrm{n}$ & s & s & $\mathrm{n}$ & $\mathrm{n}$ & TRUE & 0.002 \\
\hline $\mathrm{n}$ & s & $\mathrm{n}$ & $\mathrm{n}$ & s & $\mathrm{n}$ & $\mathrm{n}$ & TRUE & 0.001 \\
\hline
\end{tabular}

Table 4. Best, worst and middle for the probability of conformity for given values of the factors. 

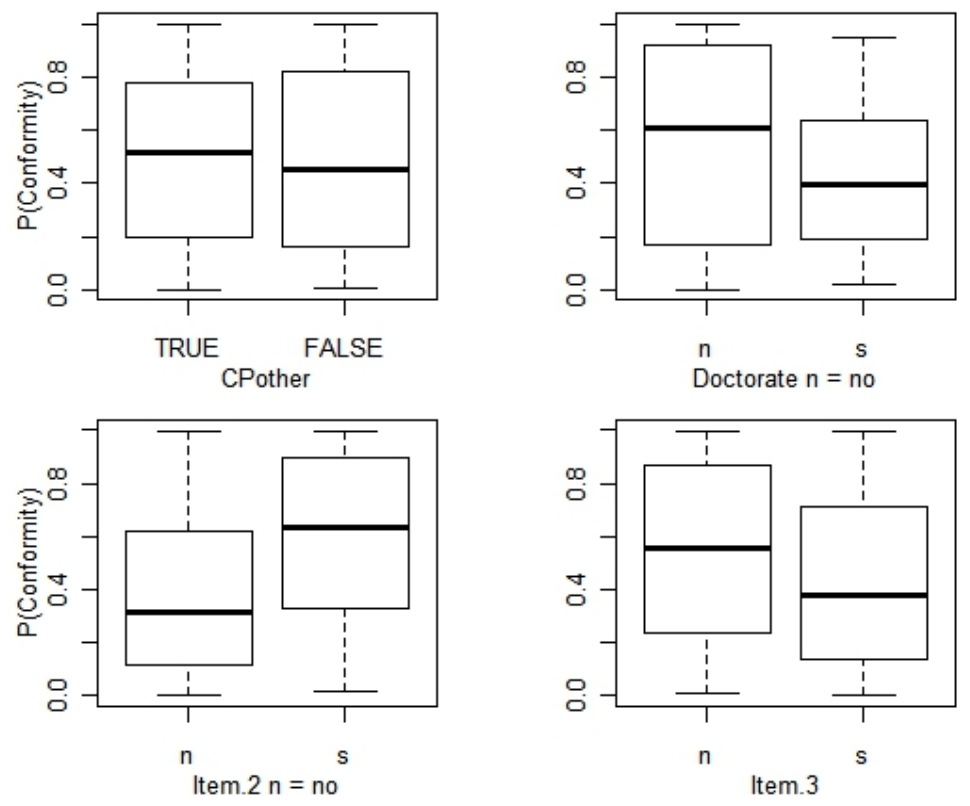

Figure 2. Box plots
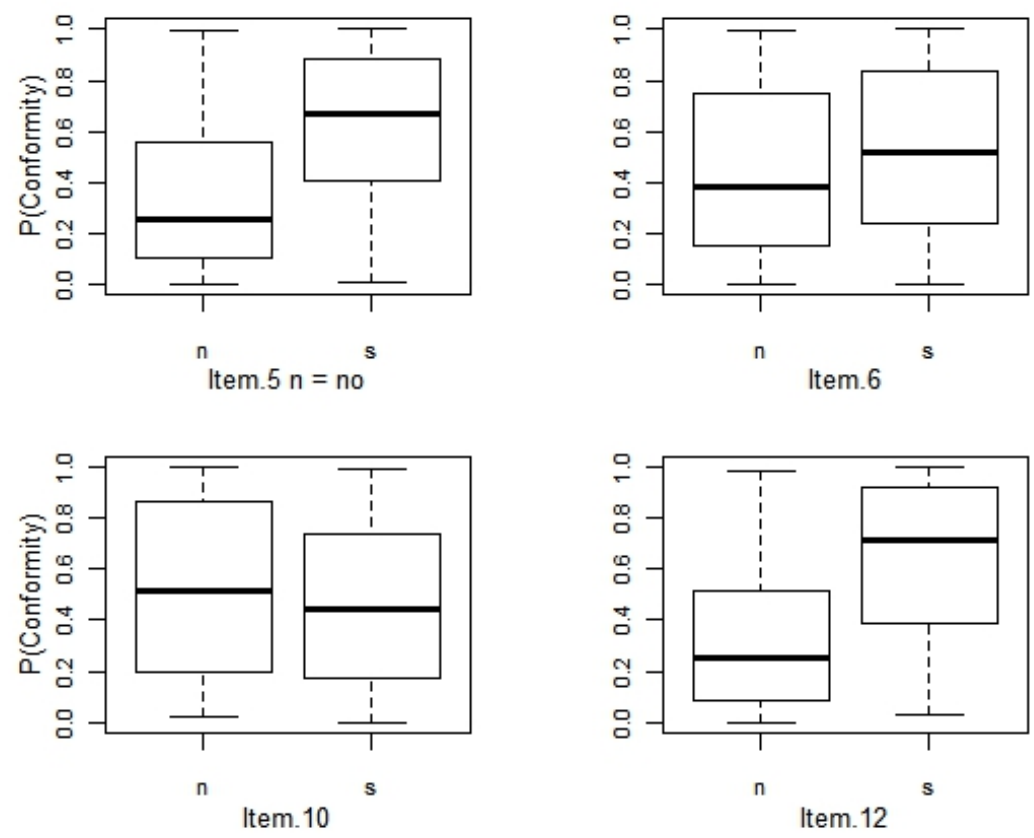

Figure 3. More Box plots

\section{Measuring differential effects of the predictors}

The influence of predictors can be represented by a finite difference equation. From equation (1)

$$
\begin{gathered}
\Delta \operatorname{logit}=\left[\ln \frac{P_{1}(c)}{1-P_{1}(c)}-\ln \frac{P_{0}(c)}{1-P_{0}(c)}\right]= \\
\mathrm{b}_{1} \Delta \mathrm{X}_{1}+\mathrm{b}_{2} \Delta \mathrm{X}_{2}+\mathrm{b}_{12} \mathrm{X}_{2} \Delta \mathrm{X}_{1} \mathrm{~b}_{12} \mathrm{X}_{1} \Delta \mathrm{X}_{2}
\end{gathered}
$$

where the value of $P_{0}(c)(=0.686)$ is the prevalence of conforming projects from the original data. The expression $\Delta X_{i}$, a binary fator, can assume values of 0 or 1 . Due to the nonlinear nature of the logistic regression, the impact of a predictor variable on the response $-\Delta P(c)$ - is not easily interpreted, however for those predictor variables that do not enter the interaction terms interpretations are more straightforward. Consider 
for example Grant Program CP00106, which has a coefficient estimate of 1.822 indicating a positive influence on the logit (table 3). The regression coefficient can be transformed into a measure of impact on the probability of conformity of financial accounts $\Delta P(c)$ given Grant Program CP00106. From equation (2),

$$
\begin{aligned}
\Delta \operatorname{logit} & =\left[\ln \frac{P_{1}(c)}{1-P_{1}(c)}-\ln \frac{P_{0}(c)}{1-P_{0}(c)}\right]= \\
\text { odds }_{1} / \text { odds }_{0} & =\mathrm{e}^{1.822} ; \quad \begin{array}{l}
1.822^{*} \Delta \mathrm{CP} 00106 \\
P_{1}(c)
\end{array}=0.931
\end{aligned}
$$

Substituting for $P_{0}(c)=0.686$ (average of approvals in all grants) and $\Delta \mathrm{CP} 00106=1$, the result is $P_{1}(c)=$ 0.931 and $P_{1}(c)-P_{0}(c)=0.931-0.686=0.245$.

Consequently, assuming that the other factors are fixed to yield the average of conformity $(0.686$, see the middle of table 4), the probability of conformity increases above the average by about 25 percentage points for grant program CP00106. See the first line of table 5 at the end of this paper.

The calculation of $P_{1}(c)$ for the factor Doc is more complicated because of the interaction terms.

$$
\Delta \operatorname{logit}=\left[\ln \frac{P_{1}(c)}{1-P_{1}(c)}-\ln \frac{P_{0}(c)}{1-P_{0}(c)}\right]=
$$

(- 3.387 + 2.7776CPother-1.9785Item $12+$

3.6977Item $10-1.4535$ Item $2+1.9751$ Item. 3$) * \Delta$ Doc $=$

1.631

$$
\text { odds } 1 / \text { odds } 0=\mathrm{e}^{1.631} \quad \rightarrow \quad P_{1}(c)=0.918
$$

Given the situation where all interaction terms are activated $($ Cpother $=$ Item $12=$ Item $10=$ Item $2=$ Item3 $=1), P_{1}(c)=0.918$ and $\Delta P(c)=P_{1}(c)-P_{0}(c)=0.232$. Here, the presence of the doctorate has a beneficial impact of about 23 percentage points on the conformity of the financial accounts. This result is on the fourth line from the bottom of table 5. On the other hand, if the situation has no interaction term activated, all equal to zero, then the presence of the doctorate causes a decline of 62 percentage points in the probability of conformity, as shown in table 5, three lines from the bottom. The last four numbers in column $\Delta \mathrm{P}$ are especially noteworthy, giving the change in probability when the coordinator has a doctorate and all or some of the items of the checklist are verified. These last entries are especially disheartening for the doctorate, diminishing the probability of conformity by more than 60 percentage points. The conclusion here seems to be that doctorates make for poor coordinators. Another question to look into would be the large disparity in the impact of specific grant programs (see the first seven impact calculations in the last two columns of table 5). Some of the largest positive and negative impacts in the table are among these numbers. Comparing prerequisites among different grant programs should unveil some relevant characteristics.

\section{Statistical process control}

Finally, a procedure for quality control is inspired from the Statistical Process Control literature (Shewhart, 1929). In control chart applications, the underlying process is assumed stable (stationary) with constant mean and variance. Periodic sample measurements that fall within a control limit show that the process is acceptable, and if measurements fall outside the limit an investigation to uncover assignable causes would be forthcoming. The placement of the limit is a question of probability: neither should the limit be too far away from the process mean resulting in undisclosed process instability, nor should it be too close to the mean producing an abundance of measurements outside the limit with no assignable cause (false alarms). We can offer operational concreteness to the theory of control limits by adjusting the control limit using the estimates from the logistic regression. Table 6 is organized to compare the probability of conformity between a base case, where all items on the checklist are approved (first line of the table), with situations characterized by one or a few rejected items. The base diff column shows by how much $P(c)$ declines when certain checklist items are not approved. The difference between the first line and the second line where item 3 is the only rejected item is a very small 0.001 , demonstrating that item 3 has no effect on the outcome. However, the seventh line in the table represents the rejection of item 5 and a decline in $P(c)$ of 0.195 , the strongest impact among the first lines of the table for individual item rejection. The first $P$ (c) less than 0.5, which might be considered a benchmark value for judging nonconformity, comes from the joint rejection of item 5 and item 12 . Item 5 should be checked first and if rejected the auditor should jump to item 12 and if also rejected the financial accounts are quickly judged nonconforming. 


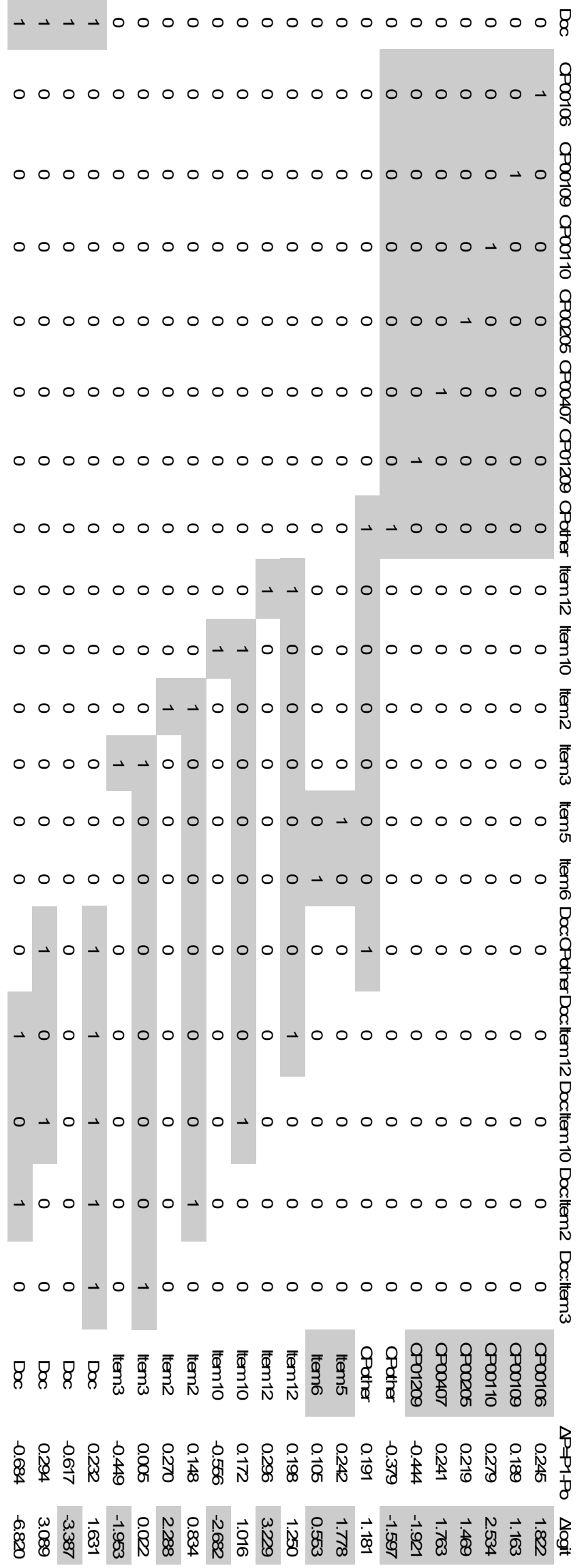


Item.2 Item. 3 Item.5 Item.6 Item.10 Item.12 Doc CPother $P(c)$ base items

$\begin{array}{ccccccccccc}\mathrm{s} & \mathrm{s} & \mathrm{s} & \mathrm{s} & \mathrm{s} & \mathrm{s} & \mathrm{s} & \text { TRUE } & 0.947 & 0 & \\ \mathrm{~s} & \mathrm{n} & \mathrm{s} & \mathrm{s} & \mathrm{s} & \mathrm{s} & \mathrm{s} & \text { TRUE } & 0.946 & 0.001 & 3 \\ \mathrm{~s} & \mathrm{~s} & \mathrm{~s} & \mathrm{n} & \mathrm{s} & \mathrm{s} & \mathrm{s} & \text { TRUE } & 0.912 & 0.035 & 6 \\ \mathrm{n} & \mathrm{s} & \mathrm{s} & \mathrm{s} & \mathrm{s} & \mathrm{s} & \mathrm{s} & \text { TRUE } & 0.886 & 0.061 & 2 \\ \mathrm{~s} & \mathrm{~s} & \mathrm{~s} & \mathrm{~s} & \mathrm{n} & \mathrm{s} & \mathrm{s} & \text { TRUE } & 0.867 & 0.08 & 10 \\ \mathrm{~s} & \mathrm{~s} & \mathrm{~s} & \mathrm{~s} & \mathrm{~s} & \mathrm{n} & \mathrm{s} & \text { TRUE } & 0.837 & 0.11 & 12 \\ \mathrm{~s} & \mathrm{~s} & \mathrm{n} & \mathrm{s} & \mathrm{s} & \mathrm{s} & \mathrm{s} & \text { TRUE } & 0.752 & 0.195 & 5 \\ \mathrm{~s} & \mathrm{n} & \mathrm{n} & \mathrm{s} & \mathrm{s} & \mathrm{s} & \mathrm{s} & \text { TRUE } & 0.748 & 0.199 & 53 \\ \mathrm{~s} & \mathrm{~s} & \mathrm{~s} & \mathrm{n} & \mathrm{s} & \mathrm{n} & \mathrm{s} & \text { TRUE } & 0.748 & 0.2 & 126 \\ \mathrm{n} & \mathrm{s} & \mathrm{s} & \mathrm{s} & \mathrm{s} & \mathrm{n} & \mathrm{s} & \text { TRUE } & 0.691 & 0.256 & 122 \\ \mathrm{~s} & \mathrm{~s} & \mathrm{~s} & \mathrm{~s} & \mathrm{n} & \mathrm{n} & \mathrm{s} & \text { TRUE } & 0.651 & 0.296 & 1210 \\ \mathrm{~s} & \mathrm{~s} & \mathrm{n} & \mathrm{n} & \mathrm{s} & \mathrm{s} & \mathrm{s} & \text { TRUE } & 0.636 & 0.311 & 56 \\ \mathrm{n} & \mathrm{s} & \mathrm{n} & \mathrm{s} & \mathrm{s} & \mathrm{s} & \mathrm{s} & \text { TRUE } & 0.569 & 0.378 & 52 \\ \mathrm{~s} & \mathrm{~s} & \mathrm{n} & \mathrm{s} & \mathrm{n} & \mathrm{s} & \mathrm{s} & \text { TRUE } & 0.524 & 0.423 & 510 \\ \mathrm{~s} & \mathrm{~s} & \mathrm{n} & \mathrm{s} & \mathrm{s} & \mathrm{n} & \mathrm{s} & \text { TRUE } & 0.465 & 0.482 & 512 \\ \mathrm{~s} & \mathrm{n} & \mathrm{n} & \mathrm{s} & \mathrm{s} & \mathrm{n} & \mathrm{s} & \text { TRUE } & 0.46 & 0.488 & 3512 \\ \mathrm{n} & \mathrm{s} & \mathrm{s} & \mathrm{s} & \mathrm{n} & \mathrm{n} & \mathrm{s} & \text { TRUE } & 0.447 & 0.5 & 21012 \\ \mathrm{n} & \mathrm{s} & \mathrm{n} & \mathrm{n} & \mathrm{s} & \mathrm{s} & \mathrm{s} & \text { TRUE } & 0.432 & 0.516 & 256 \\ \mathrm{~s} & \mathrm{~s} & \mathrm{n} & \mathrm{n} & \mathrm{n} & \mathrm{s} & \mathrm{s} & \text { TRUE } & 0.388 & 0.56 & 5610 \\ \mathrm{~s} & \mathrm{~s} & \mathrm{n} & \mathrm{n} & \mathrm{s} & \mathrm{n} & \mathrm{s} & \text { TRUE } & 0.334 & 0.614 & . .512 \\ \mathrm{n} & \mathrm{s} & \mathrm{n} & \mathrm{s} & \mathrm{n} & \mathrm{s} & \mathrm{s} & \text { TRUE } & 0.323 & 0.624 & 2510 \\ \mathrm{n} & \mathrm{s} & \mathrm{n} & \mathrm{s} & \mathrm{s} & \mathrm{n} & \mathrm{s} & \text { TRUE } & 0.274 & 0.673 & . .512 \\ \mathrm{n} & \mathrm{n} & \mathrm{n} & \mathrm{n} & \mathrm{n} & \mathrm{n} & \mathrm{s} & \text { TRUE } & 0.071 & 0.876 & . .512\end{array}$

Table 6. Probability of conformity for some cases, control chart construction.

However, a question remains unanswered: What is the best cutoff probability $P(c)$ that reduces the probability of error as judging good projects nonconforming and bad projects conforming. In the next section, this question is analyzed with the help of the Receiver Operator Characteristic (ROC) curve, ubiquitous in the health sciences but unfortunately rarely seen elsewhere.

\section{The receiver operator characteristic (ROC) curve}

Ziliak (2012) and Ord (2012) commenting on a special section of The International Journal of Forecasting with lead article by Soyer and Hogarth (2012) have recently called for more graphical analysis instead of the mechanical style of hypothesis testing common in Social Science research. They argue that graphical analysis may be easier to understand than a list of statistics and $\mathrm{p}$ values, and furthermore when wellelaborated a graphical analysis may even be more complete and more transparent. ROC analysis has been growing in popularity as one of many methods that respond to the challenges of graphical analysis. An interesting introduction can be found in Swets, et al (2000) and a pioneering application in crime forecasting can be found in Gorr, W. L. (no date) and Cohen, et al (2009).

In the health sciences, a test which shows a positive result means that a medical condition or a specific substance has been indicated. A patient tests positive for cancer, an athlete positive for hormone abuse. One might say that a positive result is analogous to the rejection of the null hypothesis, the null being that the patient is healthy or the athlete is free of prohibited substances. The null hypothesis of the bureaucratic 
procedure described in this paper is that financial accounting by the researcher is conforming. Generally speaking, objects in a sample are classified as either positive or negative by a test. The true positives and negatives in the sample will surely not coincide perfectly to the test results, some errors of classification will certainly appear. Therefore, the correct application of ROC analysis requires that the classification of individual elements be known, for instance which patients are healthy or which athletes are free of drugs. The true classification is usually known after more tests are performed and conclusions are held with more certainty. The data in this paper were classified as financial accounts that are either conforming (c) or nonconforming (n). In ROC analysis, there are at least two ways to measure the overall accuracy of a test. Tests can be graded on the basis of the true positive rate $\mathrm{TPR}=\mathrm{TP} / \mathrm{P}$ which measures the "sensitivity" (power) of the test, and answers the question of how many positives were correctly determined (TP) within the group of positives $(\mathrm{P})$. Tests can also be graded on the true negative rate $\mathrm{TNR}=\mathrm{TN} / \mathrm{N}$ called a measure of "specificity".

Tests commonly result in numerical values that dictate whether the test object is positive or negative. Usually tests are set up so that large values of the numerical result indicate a positive, and small measures indicate negative. Consequently, the choice of the cutoff value which separates positive from negative is a pivotal decision for optimizing the accuracy of the test. If the cutoff value is too large then mistakes will occur that overemphasize negatives, false negatives (FN) will prevail, and consequently only a small number of false positives (FP) will be produced. On the other hand, if the cutoff value is too small, then positives will be produced in abundance and among them many false positives (FP), also known as false alarms and Type I error. However false negatives (FN), Type II error, will be diminished in number since there is an inverse relationship between FP and FN. Abdi (2007) refers to decision processes as liberal or conservative considering whether they allow for relatively large numbers of FP or relatively small, respectively. In many areas of Science, the cutoff value is fixed to produce a maximum of 5\% for the false positive rate $\mathrm{FPR}=\mathrm{FP} / \mathrm{N}$ also known as the level of significance alpha (FPR $=1-\mathrm{TNR})$, the area in the tail of the null distribution, representing a maximum cutoff value for not rejecting the null hypothesis. In other words, Economists tend to accept the liberal approach to decision making, while in engineering and especially Statistical Process Control, the cutoff value is fixed to reflect a FPR of only $0.27 \%$ (approximately one quarter of one per cent), representing a conservative approach. The other side of the question is the false negative rate (FNR) also in some circumstances called beta (= $1-$ TPR $=1$ - "sensitivity"). McCloskey and Ziliak complain that Economists who mechanically use the 5\% FPR, simply ignore the existence of the false negative rate (FNR) which for some applications may approach $100 \%$ but is not reported as relevant information in published works. ROC analysis allows for an appreciation of both Type I and Type II error. Using a utility-disutility-cost function that weighs differently the relative importance of false negatives and false positives depending upon the situation under study and the preferences of the decision maker, an optimal cutoff value can be chosen. In a later section, we will develop the function of weights (Metz,1978), and show that its structure also depends upon the prevalence of true negatives and positives in the population.

\begin{tabular}{|c|c|c|c|}
\hline & \multicolumn{2}{|c|}{ REALITY WITHIN THE SAMPLE } & \\
\hline & $\begin{array}{l}\text { TRULY POSITIVE } \\
\text { (nonconforming) }\end{array}$ & $\begin{array}{l}\text { TRULY NEGATIVE } \\
\text { (conforming) }\end{array}$ & \\
\hline $\begin{array}{l}\text { TESTED AS } \\
\text { POSITIVE }\end{array}$ & $\begin{array}{l}\text { TP }(\text { hits }) \\
\mathrm{TP} / \mathrm{P}=\text { sensitivity }\end{array}$ & $\begin{array}{l}\text { FP (false alarm) } \\
\text { FP/N = 1- specificity } \\
\text { alpha }\end{array}$ & $\begin{array}{l}\text { TOTAL TESTED } \\
\text { POSITIVE }\end{array}$ \\
\hline \multirow[t]{2}{*}{$\begin{array}{l}\text { TESTED AS } \\
\text { NEGATIVE }\end{array}$} & $\begin{array}{l}\mathrm{FN} \\
\mathrm{FN} / \mathrm{P}=1 \text { - sensitivity } \\
\text { beta }\end{array}$ & $\begin{array}{l}\text { TN } \\
\text { TN/N = specificity }\end{array}$ & $\begin{array}{l}\text { TOTAL TESTED } \\
\text { NEGATIVE }\end{array}$ \\
\hline & $\mathrm{TP}+\mathrm{FN}=\mathrm{P}$ & $\mathrm{FP}+\mathrm{TN}=\mathrm{N}$ & $\mathrm{N}+\mathrm{P}=\mathrm{TOTAL}$ \\
\hline
\end{tabular}

Table 7. Tests and the truth: ROC concepts. 


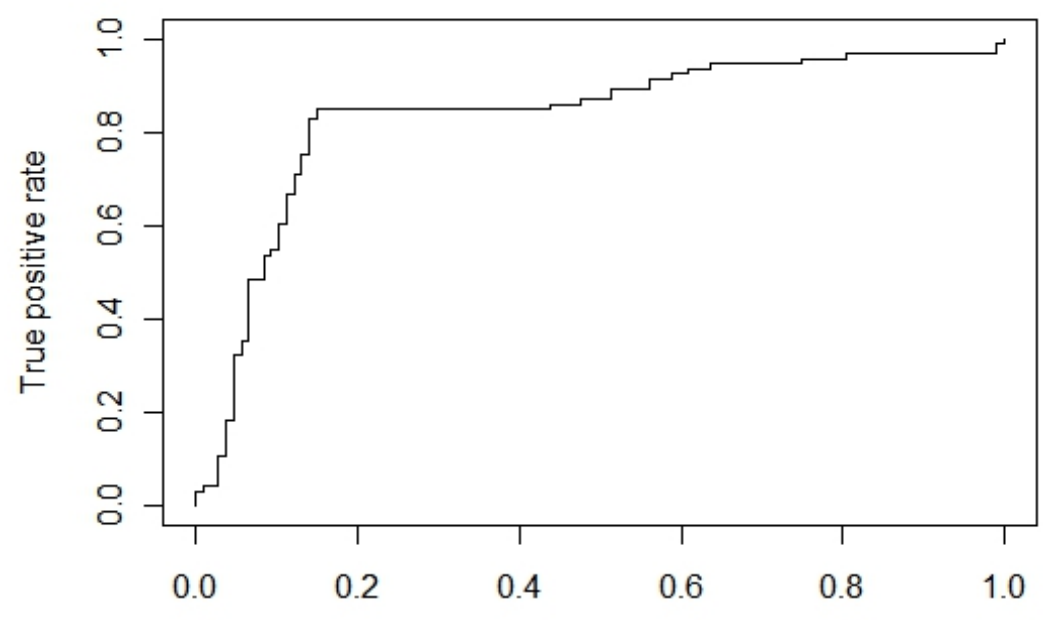

False positive rate

Figure 4. Example ROC curve from R Graph Gallery (2012), T. Sing, et al (2005)

Diminishing the number of false positives and false negatives is the goal of quality audits, which simultaneously will maximize true positives and true negatives. In the context of quality audits, false positives (condemning good accounts) are considered relatively minor errors from the auditor's point of view, because this kind of error can be fixed later at little expense to the auditor, whereas false negatives are much more prejudicial. Once an auditor has $\mathrm{OK}^{\prime}$ ed financial accounts that are in fact bad, there is no second chance to catch this mistake. Consequently, from the point of view of the auditor, the cost of the false negative is much greater than the cost of the false positive. However, even though the false positive is very costly to the researcher who will have to defend himself against the negative determination of the auditor, who determines the weights, is the auditor not the researcher. A cutoff value is defined in an optimal sense to classify conforming and nonconforming financial accounts. The value of the cutoff will be chosen to minimize a combination of false positives and false negatives from the point of view of the auditor. The ROC curve is drawn as the relationship between FPR the false alarm rate and $1-$ FNR the true hit rate. A stylized version is given in figure 4, with the horizontal axis representing the rate of false alarms (FPR) and the vertical axis representing the hit rate $(1-\mathrm{FNR}=\mathrm{TPR})$. In the figure, starting at the origin, a decision maker would be interested in knowing that a small increase in the FPR would result in a corresponding but much greater TPR up to a value of FPR of approximately 0.2 and corresponding TPR of 0.8 . The choice of TPR and FPR is made by selecting the appropriate cutoff value. In the next section, a method is presented for choosing an optimal pair of FPR and TPR by fixing the cutoff value based on a subjective evaluation of the perceived costs of FP (false alarms) and FN.

\section{Optimizing in the choice of FP and FN}

By choosing the relative costs of FP and FN from the point of view of the decision maker, an optimal point can be chosen along the ROC curve. Cohen, et al (2009) use a utility function approach that takes into account marginal utility and disutility from each result of table 7, but here we will apply a simpler cost equation, without loss of generality. Define a total cost function based on FP and FN,

$$
C T=F P+R \quad F N
$$

where $\mathrm{R}$ is the perceived cost of FN, and the cost of FP is unitary. The application here uses $\mathrm{R}>1$ since the auditor will attribute FN with much more onus than FP, as suggested in the previous section. For an interesting example in the context of natural disasters of an attempt to quantify costs of FP (announce an evacuation that is not necessary, false alarm) and FN (no evacuation is announced but disaster strikes) see Regnier (2008). To show the proportion $(p)$ of positives $(P)$ in the total and redefining cost as unitary $(C)$,

$$
C=F P R(1-p)+R \text { FNR } p
$$

Furthermore, rearranging in terms of TPR,

$$
T P R=\frac{(R p-C)}{R p}+\frac{F P R(1-p)}{R p}
$$


This equation, often called a cost constraint, if placed in figure 4 would be a straight line with intercept at $\frac{(R p-C)}{R p}$ and slope equal to $\frac{(1-p)}{R p}$. Along a given cost constraint costs are constant. Costs are minimized and consequently TPR and FPR are at optimal values when the ROC curve is just tangent to equation (8). At the optimal point, the slope of (8) $\frac{(1-p)}{R p}$ is equal to the slope of the ROC curve. This means that as $p$ approaches 1.0 and as $R$, the perceived cost of FN, increases, optimal values of TPR and FPR increase (FNR decreases). In the classification problem studied here, the major determinant for the values of FPR and FNR is the cutoff value, when too large false negatives will appear in excess and, to the contrary, when too small false positives will be exaggerated. In order to choose the correct value of the cutoff, the elements of the cost function will be assigned values either from sample estimates or from the preferences of the decision making auditors. In the next section, the empirical ROC curve will be constructed.
Throughout this section, statistical results and analysis depend upon the $\mathrm{R}$ language ( $\mathrm{R}$ Development Core Team (2012)) and the ROCR package by Sing, et al (2005). The ROC curve quantifies the tradeoff between false alarms FPR and hits TPR. As explained above the ROC curve shows how many false alarms must be tolerated in order to reach a certain level of test reliability to recognize the presence of the positive state. In the context of this article, the object to be tested or classified is the financial report associated with a research grant. The test classifies the report as conforming or nonconforming. The measurements of the test are based on the estimated logistic regression. The result of the test is the probability of conformity $P(c)$. In order to be aligned with the literature on ROC curves, the result of the test will be defined as $P(n)$ the probability of non-conformance, as presented here the non-conforming financial report. It would seem justifiable to use $P(n)=0.50$ as the cutoff between conforming and nonconforming as in table 6. This case is illustrated in figure 5 .

\section{Estimates of the ROC curve.}
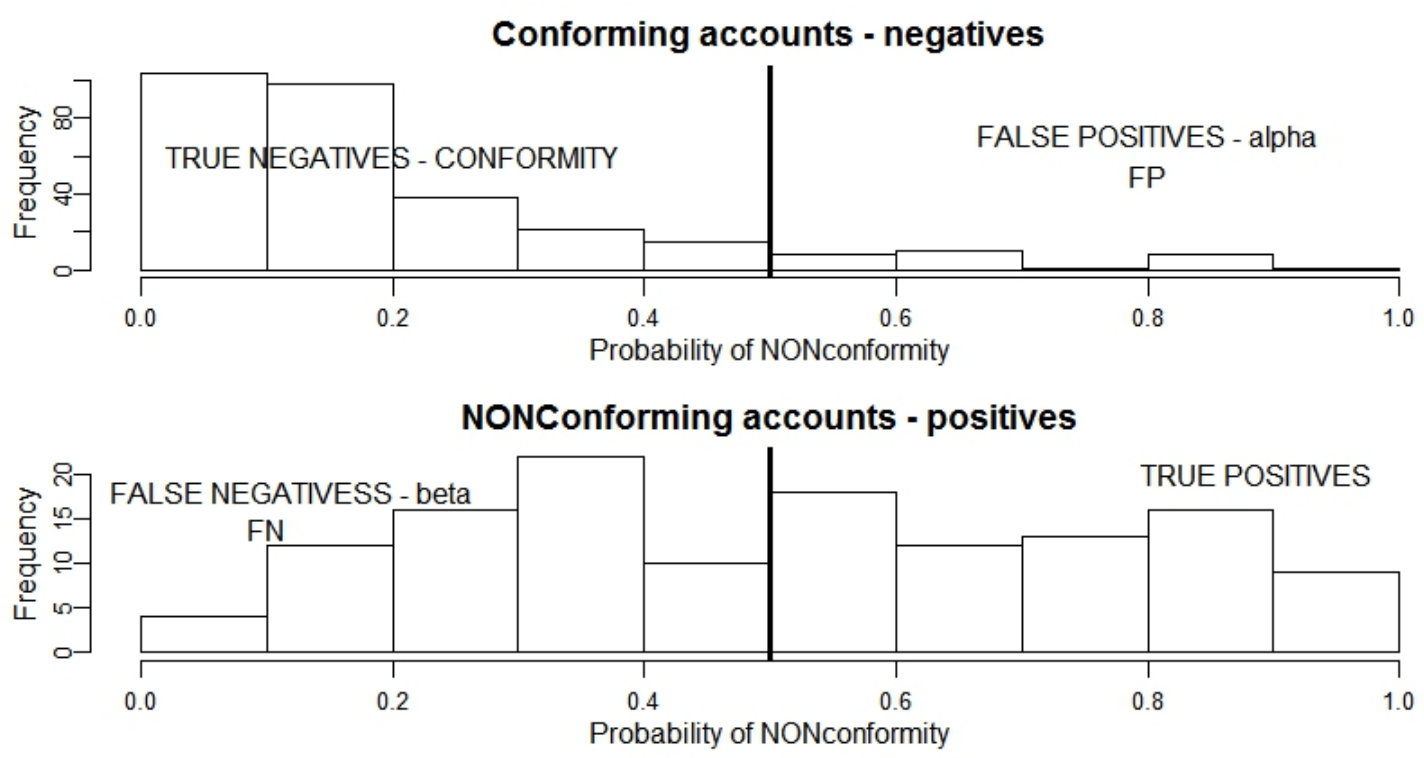

Figure 5. Separate histograms for the probability of nonconformity of positives and negatives, cutoff at 0.5 .

Two separate histograms have been constructed to illustrate the probability of non-conformance for conforming accounts in the upper part of the figure and for nonconforming in the lower. The histogram on conforming accounts shows a reduced number of false positives, characterized by large nonconforming probability indicating accounts rejection even though the accounts had been originally approved as conforming by the staff, the false positive (FP). This small number of FP's seems counterproductive since FP's cause little cost to the staff as explained above. One might consider diminishing the cutoff value to less than 0.5 allowing an increase in relatively cheap FP's and consequently diminishing the corresponding FN's in the lower histogram of nonconforming accounts. Diminishing the number of FN's seems the correct approach given their prejudicial status from the point of view of the staff. Another way of seeing the same result 
is by constructing box plots for the same set of data used in the histograms. As was apparent from the histograms, the distribution of conforming accounts is much skewed whereas the distribution of nonconforming is symmetric. Once again, diminishing the cutoff based on the probability of non-conformance will increase low cost FP but decrease costly FN. The ROC curve presented in figure 7 offers a better view of the tradeoff between FP and FN. Curvature is relatively pronounced which implies that the relationship between the estimates of the logistic regression and the categorization of the data is not random. When tests are perfect, the ROC curve is pushed into the northwest corner $(\mathrm{FPR}=\mathrm{FNR}=0)$. When tests are worthless, no better than a random draw, the ROC curve becomes a straight line with origin at zero and slope equal to one. There is much relevant literature on the statistical analysis of ROC curves not elaborated in this article but an excellent reference is Kumar, R. and A. Indrayan (2011). For low values of FPR and TPR in ROC curves with accentuated curvature, allowing for a small increment in FPR would result in a relatively large increase in TPR, a situation that the decision maker may accept enthusiastically. However, as FPR increases, the return to TPR declines accordingly. Hence, the optimal combination of FPR and TPR is a point on the ROC curve that satisfies minimum cost as perceived by the decision maker. In figure 7 , two cost constraints (equation 8) have been superimposed. The steeper constraint labeled $\mathrm{R}=1$ represents weights that are equal between FP and FN, no preference is manifested disfavoring either one of the false results. Since costs are constant along the constraint, the optimal combination of TPR and FPR is not uniquely defined. The flatter curve represents $R=5$ which is the realistic perception of the staff, FN is 5 times more important (more costly) than FP (equation 8). Logically, this case should produce an FPR larger and an FNR smaller. The values as shown in figure 8 are in fact 0.34 and 0.89 for the FPR and the TPR, respectively. FNR $(=1-$ TPR $)$ is reduced to 0.11 .

As explained above at the end of section 7, the optimal combination of FPR and TPR corresponds to a certain cutoff, and from figure 8 , where horizontal lines have been drawn at the values of the optimal combination, visual inspection reveals that the cutoff should be 0.20 . Consequently, when $P(n)$ calculated from the logistic regression is less than $0.20(P(c)$ greater than 0.80$)$ then financial accounts should be judged as conforming, otherwise they are non-conforming. The cutoff may seem very different from the intuitive value of $50 \%$, however this is the value that best reflects the preferences of the decision makers. Returning to table 6 , readjusting the cutoff to 0.20 would mean that if any item were rejected individually then a judgment of nonconformance would be forthcoming.

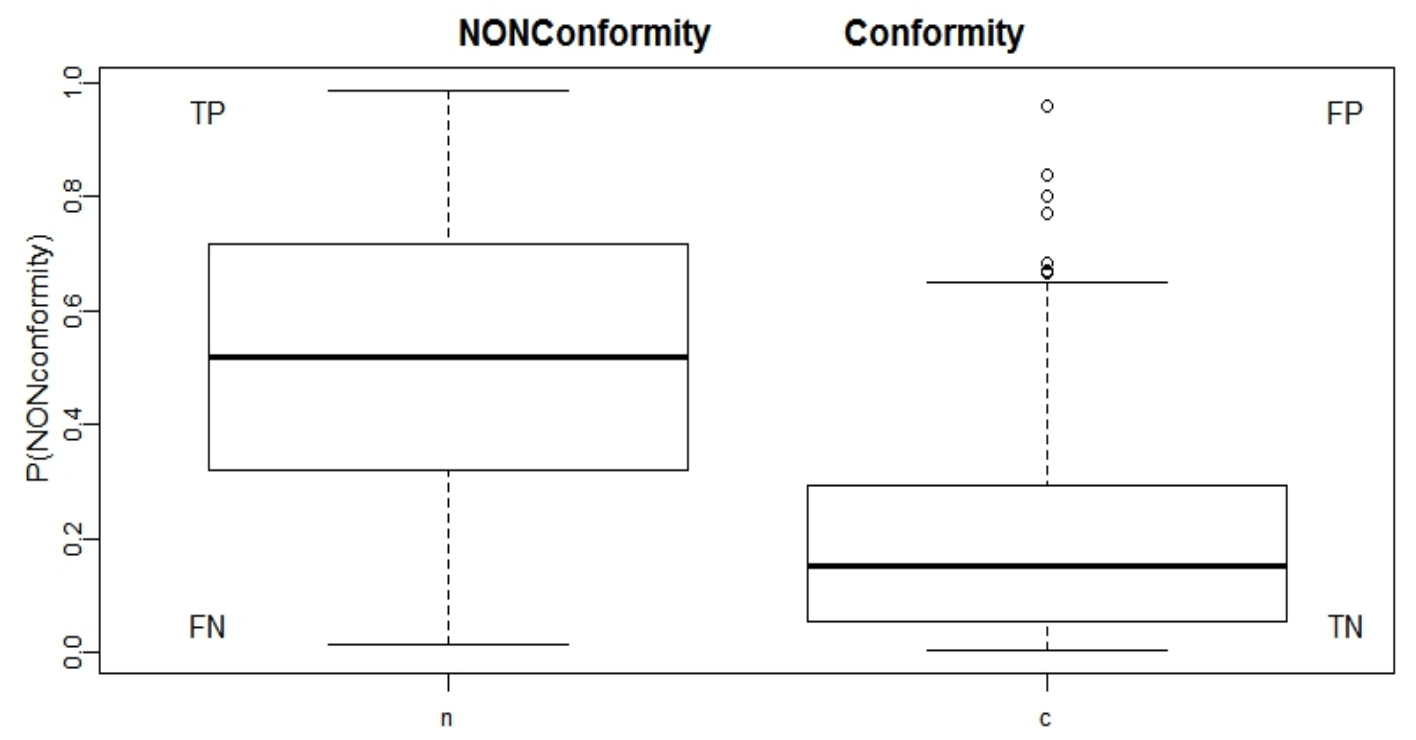

Figure 6. Box plots. 


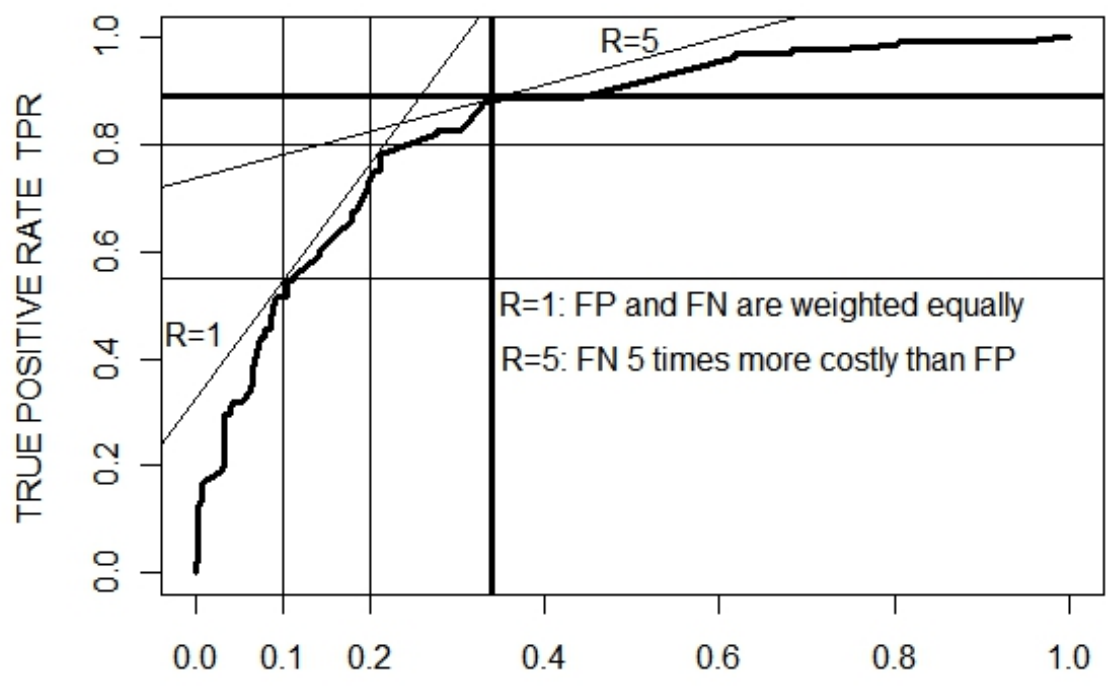

FALSE POSITIVE RATE FPR

Figure 7. ROC curve.
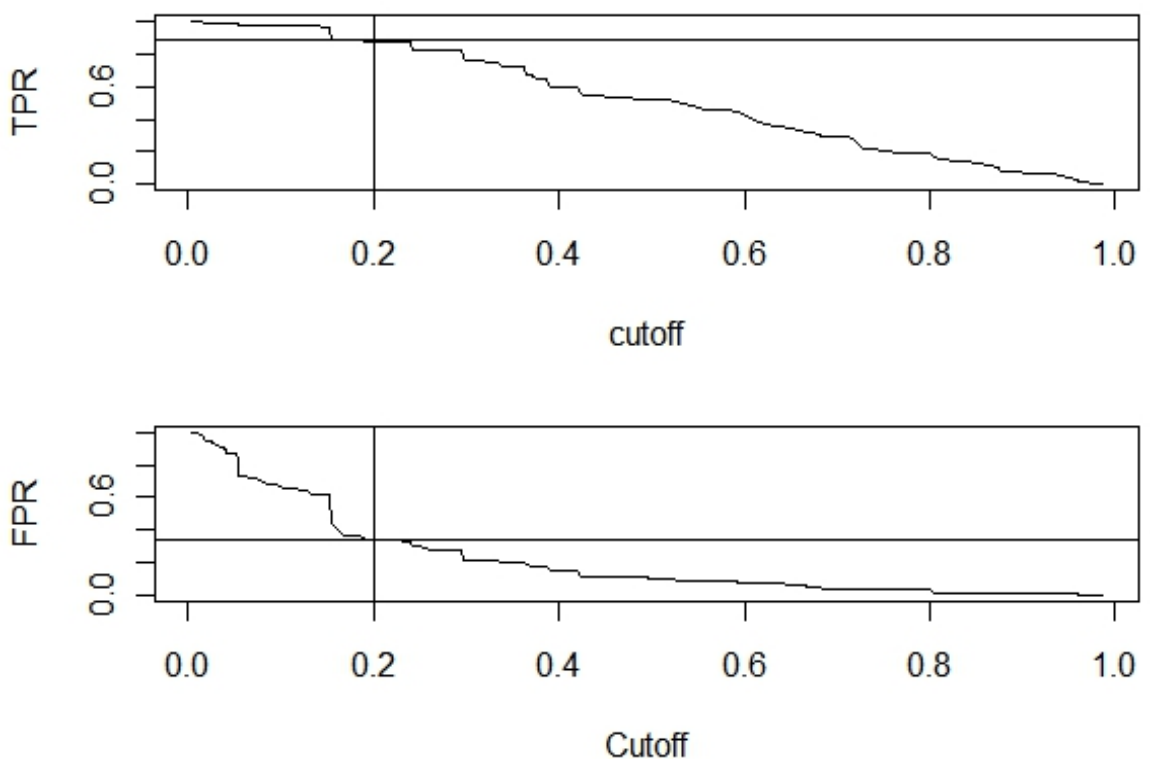

Figure 8 . False positive rate and true positive rate as functions of the cutoff.

\section{Conclusions}

The analysis has disclosed several avenues for making the verification of financial accounts faster and more accurate. First, the discrepancy between true positives and negatives, and the approval or rejection of specific items in the checklist may have its origin in operational definitions, analogous to the calibration of measurement instruments on the assembly line. With a renovated and updated checklist, procedures can be streamlined and made more reliable. Prime targets are those items which demonstrate no relationship with the classification of the financial accounts or possess a counter-intuitive signal. The operational order of the checklist items should reflect the impact they have on the probability of nonconformance. Larger impacts should correspond to 
priority items, thus eliminating the necessity of reviewing all items. The project coordinator with a doctorate presents a predicament for conformance. There is a definite tendency to connect the doctorate with non-conformance. Why this occurs may be for a psychologist to decide, but the fact is verified.

\section{References}

[1] Abdi, H. (2007). Signal Detection Theory, Encyclopedia of Measurement and Statistics, 8, pp. 313-324.

[2] Agresti A (2002). Categorical Data Analysis. JohnWiley \& Sons, Hoboken, New Jersey, 2nd edition.

[3] Cecchini, M., H. Aytug, G. J. Koehler, and P. Pathak, (2010). Detecting Management Fraud in Public Companies, Management Science, vol. 56, no. 7, pp. 1146-1160, May

[4] Cohen, J., S. Garman, and W. Gorr (2009), Empirical calibration of time series monitoring methods using receiver operating characteristic curves, International Journal of Forecasting, vol. 25 , no. 3, pp. 484-497.

[5] Cramer,J. S. (2003) The origins and development of the logit model, Bliss, August. pp. $1-19$

[6] Deming, W. Edwards (1990). Qualidade: A revolução da Administração. Rio de Janeiro, Editora Marques-Saraiva.

[7] Dionne, G., F. Giuliano, and P. Picard (2008), Optimal Auditing with Scoring: Theory and Application to Insurance Fraud, Management Science, vol. 55, no. 1, pp. 58-70.

[8] Gelman, Andrew, James S. Liebman, Valerie West, and Alexander Kiss (2004) A Broken System: The Persistent Patterns of Reversals of Death Sentences in the United States, Journal of Empirical Legal Studies, Volume 1, Issue 2, 209-261, July

[9] Gorr, Wilpen L. (no date) Forecasting Exceptional Demand Based on Receiver Operating Characteristics ROC. working paper, pp. 1-15.

[10]Hastie, T., R. Tibshirani, AND J. Friedman, (2008) The Elements of Statistical Learning. Stanford, California

[11]Komori, O. (2009) A boosting method for maximization of the area under the ROC curve, Annals of the Institute of Statistical Mathematics, vol. 63, no. 5, pp. 961-979, Oct.
[12]Kumar, R. and A. Indrayan, (2011) Receiver operating characteristic (ROC) curve for medical researchers., Indian Pediatrics, vol. 48, no. 4, pp. 277-287.

[13] Ord, J. Keith The illusion of predictability: (2012). A call to action. International Journal of Forecasting, Volume 28, Issue 3, JulySeptember, Pages 717-718

[14]R Development Core Team (2012) R: A Language and Environment for Statistical Computing. R Foundation for Statistical Computing, Vienna, Austria. ISBN 3-90005107-0. URL http://www.r-project.org/.

[15]R Graph Gallery (2012), http://addictedtor.free.fr/graphiques/RGraphGa llery.php?graph=99, visited 8-28-12.

[16]Reed, L. J. and J. Berkson (1929). The application of the logistic function to experimental data. Journal of Physical Chemistry 33, 760-779.

[17]Regnier, E. Public Evacuation Decisions and Hurricane Track Uncertainty, Management Science, vol. 54, no. 1, pp. 16-28, Jan. 2008.

[18] Samohyl, R.W. (2009). Controle Estatístico de Qualidade. Rio de Janeiro: Elsevier.

[19] Shewhart, W. (1931). Economic control of quality of manufactured product. New York: D. Van Nostrand Company.

[20] Sing, Tobias, Oliver Sander, Niko Beerenwinkel, Thomas Lengauer (2005). ROCR: visualizing classifier performance in $\mathrm{R}$. Bioinformatics 21(20): 3940-3941

[21] Sing, Tobias, Oliver Sander, Niko Beerenwinkel and Thomas Lengauer. (2009). Package ROCR: Visualizing the performance of scoring classifiers. Version dated 08-Dec2009. Available at: http://cran.r project.org/web/packages/ROCR/.

[22] Soyer, Emre, Robin M. Hogarth (2012). The illusion of predictability: How regression statistics mislead experts International Journal of Forecasting, Volume 28, Issue 3, JulySeptember,Pages 695-711

[23]Ziliak, Stephen T. Visualizing uncertainty: On Soyer's and Hogarth's The illusion of predictability: How regression statistics mislead experts, International Journal of Forecasting, Volume 28, Issue 3, JulySeptember, pages 712-714 